\title{
Role of Female Community Health Volunteers for Prevention and Control of COVID-19 in Nepal
}

*Surya B Parajuli ${ }^{1}$, Sabin Shrestha ${ }^{2}$, Anisha Sah ${ }^{2}$, Heera $\mathrm{KC}^{3}$, Kapil Amgain ${ }^{4}$, Prajjwal Pyakurel ${ }^{5}$

${ }^{1}$ Assistant Professor, Department of Community Medicine, Birat Medical College \& Teaching Hospital, Nepal

${ }^{2}$ Intern, Department of Community Medicine, Birat Medical College \& Teaching Hospital, Nepal ${ }^{3}$ Lecturer, Department of Nursing, Birat Health College, Purbanchal University, Nepal

${ }^{4}$ Assistant Professor, Department of Clinical Anatomy and Cell Biology, Karnali Academy of Health Sciences

${ }^{5}$ Assistant Professor, School of Public Health and Community Medicine, B. P. Koirala Institute of Health Sciences, Nepal

\section{*Corresponding author:}

Dr Surya B. Parajuli, Assistant Professor, Department of Community Medicine

Birat Medical College \& Teaching Hospital, Kathmandu University

Email: drsathii@yahoo.com

https://orcid.org/0000-0003-0386-9273

\begin{abstract}
Female Community Health Volunteers (FCHVs) are the pillars of community health programs in Nepal who play a pivotal role in implementing various community based preventive, promotive and curative health programmes. In the context of COVID 19 pandemic and possible outbreak in Nepal, the only way by which it can be stopped at the moment is by prevention. This paper presents the role of FCHVs for the prevention and control of COVID 19 in Nepal.
\end{abstract}

Key words: Control, COVID 19, FCHVs, Nepal, Prevention

\begin{tabular}{|l|l|l|}
\hline \multicolumn{2}{|c|}{ Access this article Online } & Article Info. \\
\hline Quick Response Code & Website: & How to cite this article in Vancouver Style? \\
\hline Www.jkahs.org.np & $\begin{array}{l}\text { Parajuli SB, Shrestha S, Sah A, KC H, } \\
\text { Amgain K, Pyakurel P. Role of Female } \\
\text { Community Health Volunteers for Prevention } \\
\text { and Control of COVID-19 in Nepal. Karnali } \\
\text { Academy of Health Sciences 2020;3(1):1-6. }\end{array}$ \\
\hline
\end{tabular}




\section{BACKGROUND}

Female Community Health Volunteers (FCHVs) are the volunteers working at community level to support health promotion and disease prevention activities over the last three decades in Nepal. ${ }^{1}$ This program was initiated with the objectives of preparing a pool of volunteers to provide health services at community level; to activate local women to solve common health problems by delivering relevant knowledge and skills; to increase participation of community people in improving health; to develop them as a motivator for health and wellness and to increase healthcare services utilization through creation of demand. ${ }^{1}$ The Government of Nepal initiated this program in fiscal year 1988/89 in 27 districts by selecting one FCHV per ward regardless of the population size. Later in 1993/94, a population based approach was introduced in selected 28 districts. By 1995, the program was established in all 75 districts. ${ }^{1}$ FCHVs are selected by members of Mothers' Group for Health (MG-H) with the help of local health facility staff. FCHVs get 18 days basic training in two phases (9+9 days) on different primary health care components. ${ }^{1}$ According to annual report 2017/18 published by the department of health services of Nepal, there are 51,420 FCHVs in the country. ${ }^{2}$ After promulgation of new constitution of Nepal, a three tier government system was initiated: federal, provincial and local. ${ }^{3}$ Village development committees (VDCs) and municipalities merged together to form a local government. Many previous wards merged together which results in more than one FCHVs within a ward. For example, in Belbari Municipality of Province 1, there are 35 female community health volunteers in 11 wards which is equivalent to 3-4 FCHVs in each ward. $^{3}$ As a responsible volunteer health workforce of the country's health system, they are currently assisting with primary health care activities and acting as a bridge between government health services and the community. They are the backbone of our health system who played a pivotal role in implementing various community based preventive, promotive and curative programmes. They were the key persons at community level for programs such as National immunization program, Birth preparedness package, Infant and young child feeding, Community based integrated management of neonatal and childhood illness, Integrated Management of Acute Malnutrition, and Family Planning. ${ }^{4}$ FCHVs have demonstrated significant roles during endemic and an epidemic situation in $\mathrm{Nepal}^{5}$ and are also considered as the backbone of Nepalese healthcare systems.

China reported the first case of coronavirus (COVID 19) to the WHO country office on December 31, 2019. ${ }^{6}$ However there are a lot of uncertainties of the origin of COVID-19 as 
China reported a 55 year old person from Huawei province as a possible index case of COVID-19 on November 17, 2019. ${ }^{7}$ WHO advised travel restriction to China on Jan 5, 2020. Later in Jan 7, 2020 the virus was identified as Coronavirus (2019-nCoV). On Jan 11, 2020, the first Coronavirus death was reported in China. WHO declared a Public Health Emergency of International Concern (PHEIC) causing pandemicity on January 30, 2020. On Feb 11, 2020, WHO accorded a name to the new Coronavirus disease: COVID-19. ${ }^{8}$ WHO declared COVID-19 as pandemic on March 11, 2020. ${ }^{8}$ Over the past four months many countries reported COVID-19 cases. The first case was reported by Thailand on 13 Jan, 2020; Japan on 15 Jan, 2020; South Korea on 20 Jan, 2020 and India on 30 Jan, 2020. Similarly, Nepal reported its first case on Jan 24, 2020.9,10 As of May 5, 2020; COVID 19 spreads to 210 countries of which 3,741,244 are confirmed cases; 258,509 confirmed deaths 1,247,310 recovered. ${ }^{11}$ The distribution of COVID-19 cases in Nepal as listed in figure $1 .^{12}$

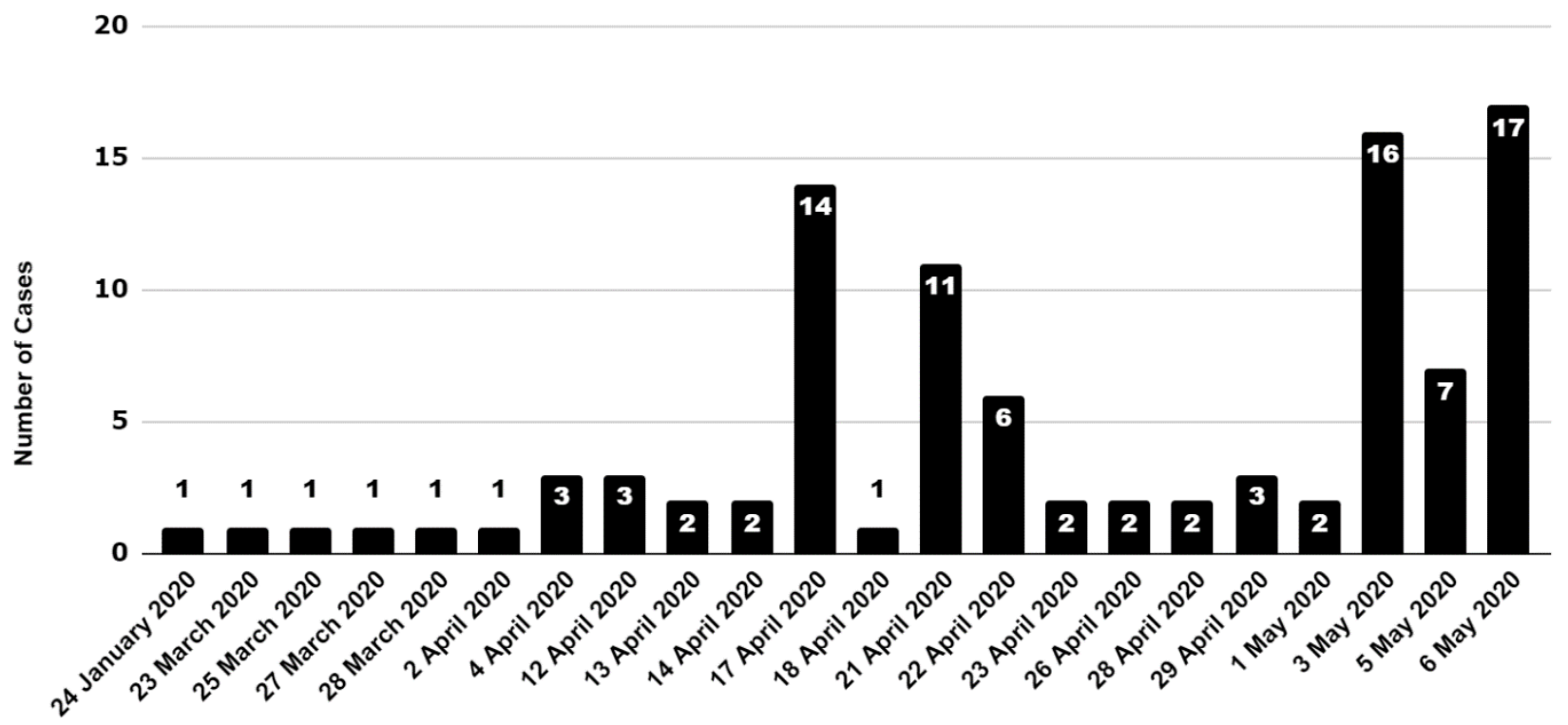

Figure 1: Distribution of COVID 19 Confirmed Cases in Nepal

\section{ROLE OF FCHVS}

People in rural municipalities of Nepal are still unaware about some of the basic principles of COVID-19 prevention. Educating the community on social distancing principles, hand hygiene and personal protective equipment measures are important components of successful community prevention of COVID-19. FCHVs are the pillars of community health programs in Nepal. Being a healthcare envoy in community settings, FCHVs play a pivotal role to prevent and control COVID 19 pandemic. Recent 
guidelines from the Ministry of Health and Population, Government of Nepal have included them as key team members of COVID-19 Prevention Group-CPG which is responsible for prevention and control of COVID 19 at ward level. ${ }^{13}$ There are innumerable qualities of FCHVs. Within their communities, they have been successful in building trust and rapport with the people in their respective stretch. They are available 24 hours and can be mobilised instantly. Many myths on COVID 19 prevail in our communities, ${ }^{14}$ which can be better addressed by FCHVs as they are native speakers who can better communicate and coordinate to a greater degree with their local people. FCHVs are culture friendly and have proven their effective counselling and motivation skills. They can be used for various preventive and promotive programs in the community such as social distancing principles, hand hygiene measures, use of personal protective equipment. FCHVs could also play an important role in creating alertness and countering stigma and blame due to COVID-19. In the period of lockdown, the routine healthcare delivery system of the government has been severely affected. Ministry of Health and Population, Government of Nepal henceforth should construct robust training and code for FCHVs so that the essential services could be resumed, and the non-essential services could be delayed. They also have existence baseline data of their community stretch and can be mapped easily for COVID-19 prevention. Since they are working as a front-line health worker, they may face various forms of imputation, segregation and can be socially blackballed in the community. So, they should be provided with extra incentive, insurance and psychological support and accolade for their service towards the community. Advantage of using FCHVs is that they could provide leverage to the Ministry of Health and Population, Government of Nepal to implement COVID 19 prevention and control program more energetically at community. However due to over burden of their work and large coverage area, technical incompetence in different aspects of health, inadequate knowledge, sometimes lack of family support, less competency in digital reporting and limited access to mass media might burn them off. Henceforth, it's the responsibility of the government to use them judiciously so that concrete output could be extracted. Additionally, utilization of FCHVs are less costly for program implementation.

\section{CONCLUSIONS}

FCHVs are the spunk of our healthcare system. They can be instrumental for prevention and control of COVID 19 infection. They can brush all the challenges in the community such as social mapping, language barrier, penetrating the social and cultural norms and bringing people on board for education, awareness and social 
mobilization. Although sometimes due to their lack of technical competencies delivering the key message in the community may be an issue but they are the epitome for community and shouldn't be disdained. We strongly recommend enrolling them into the government COVID 19 insurance health scheme which will help them to discharge their duties with full passion, dedication and commitment.

\section{REFERENCES}

1. FCHV - Family Health Division [Internet]. [cited 2020 Apr 8]. Available from:

http://www.fhd.gov.np/index.php/en/2014-03-2109-41-44/fchv

2. Department of Health Services. Annual Report [Internet]. 2017 [cited 2020 Apr 8]. Available from: https://dohs.gov.np/wpcontent/uploads/2019/07/DoHS-Annual-ReportFY-2074-75-date-22-Ashad-2076-for-web-1.pdf

3. Constitution of Nepal - Nepal Law Commission [Internet]. [cited 2020 Apr 8]. Available from: http://www.lawcommission.gov.np/en/archives/c ategory/documents/prevailinglaw/constitution/constitution-of-nepal

4. Khatri RB, Mishra SR, Khanal V. Female Community Health Volunteers in CommunityBased Health Programs of Nepal: Future Perspective. Front Public Health. 2017 Jul 21;5:181.

5. Omer M, Kroeger A, Joshi AB, Das ML, Younis LG, Singh VK, et al. Role of female community health volunteers for visceral leishmaniasis detection and vector surveillance in Nepal. Health Promot Perspect. 2020 Jan 28;10(1):50-8.
6. WHO. Novel Coronavirus, situation report 1 [Internet]. 2020 Jan [cited 2020 Apr 6].

Available from:

https://www.who.int/docs/defaultsource/coronaviruse/situation-reports/20200121sitrep-1-2019-ncov.pdf?sfvrsn=20a99c10_4

7. Davidson H. First Covid-19 case happened in November, China government records show report [Internet]. the Guardian. 2020 [cited 2020 May 5]. Available from: http://www.theguardian.com/world/2020/mar/13/ first-covid-19-case-happened-in-novemberchina-government-records-show-report

8. Coronavirus [Internet]. [cited 2020 Apr 8]. Available from:

https://www.who.int/emergencies/diseases/novelcoronavirus-2019

9. World Health Organisation. Novel Corona Virus Situation Update 1 [Internet]. 2020 Jan [cited 2020 Apr 9]. Available from: https://www.who.int/docs/defaultsource/coronaviruse/situation-reports/20200121sitrep-1-2019-ncov.pdf?sfvrsn=20a99c10_4

10. Reid D. India confirms its first coronavirus case [Internet]. CNBC; 2020 [cited 2020 Apr 9].

Available from:

https://www.cnbc.com/2020/01/30/indiaconfirms-first-case-of-the-coronavirus.html

11. Coronavirus Update [Internet]. [cited 2020 Apr 8]. Available from: https://www.worldometers.info/coronavirus/

12. Corona Info- Ministry of Health and Population [Internet]. [cited 2020 May 5]. Available from: https://covid19.mohp.gov.np/

13. Ministry of Home Affairs, Nepal. Guideline for Community Volunteer involvement for COVID 19 Prevention and Control 2076 [Internet]. [cited 2020 Apr 18]. Available from: 
http://moha.gov.np/public/upload/e66443e81e8cc rticle/view/211/131

9c4fa5c099a1fb1bb87/files/COVID_Guidline_20

76.pdf

14. View of Myths versus Truths regarding the

Novel Coronavirus Disease (COVID-2019)

Outbreak [Internet]. [cited 2020 Apr 29].

Available from:

https://www.jkahs.org.np/jkahs/index.php/jkahs/a 